\title{
New Frontiers of Security for Banks and Insurance Companies
}

\author{
by Alfonso Desiata*
}

\section{Introduction}

The need to make banking and insurance business more "secure" is beginning to be felt in more than one quarter. After more than a decade of deregulation which has finally become operative in the banking and insurance sectors after considerable struggle, and given increasingly frequent crises in the operative units of both sectors, the political world, the supervisory authorities, and the accounting and auditing associations are all now demanding reinforcement of solvency protection for both banking and insurance business.

1. An increase in the minimum capital required for the incorporation of new insurance companies and banks;

2. Reinforcement of the minimum solvency margin (MSM);

3. Low risk structure for assets;

4. Criteria for asset and liability evaluation;

5. Formation of reserves of financial equilibrium (RFE);

6. Formation of actuarial reserves of equilibrium;

7. The processing and promotion of sector ratings.

The changes in economic life that have come about over the last 20 years and which now make unavoidable reflection about the seven operative items just listed may be summarised as follows:

a. The transition to an economy of services;

b. Deregulation in the banking and insurance sectors;

c. Extension of the models of distribution;

d. Formation of a single insurance and capital market;

e. Increased volatility of financial and currency markets;

f. Increase of "system-risk" or "domino-risk";

g. In the future, some highly innovative modifications are expected in both sectors, to the extent even that some believe that bank and insurance companies will soon operate under the same institutional roof. According to the modern theory of risk management, banks are at the centre of risk systems, for it is precisely their assets and

* President, Alleanza Assicurazioni SpA, Milan. 
liabilities which are most exposed to credit and market risk. We find that an analogous balance obtains in the insurance sector between technical risks (insurance's liabilities) and financial risks (its assets).

Financial activity is the single source of this great division of risk, handled sometimes by the bank and sometimes by the insurance company. And if risk stems from a single source, then, it is argued, its management should be handled by a single body.

We have already witnessed, and witness still, great changes in the market system in Italy. It is no wonder indeed that bringing extra competition into the banking and insurance sector has inevitably meant greater likelihood of financial crisis for the institutions concerned: in the USA since 1990, 105 life insurance companies out of a total of 2,600 and 74 non life-insurance firms out of a total of 3,800 have been declared to be "struggling". A similar situation obtains for banks in the USA and for both sectors in Europe.

Since it strikes the collective imagination more readily, a crisis in the banking sector is always more apparent. System or "domino" risk which affects the operative units in a system like dominoes, can lead to the collapse of the system of payınent. In turn, signs of trouble in the payments system may lead to odd behaviour from depositors and from those financial bodies which normally handle large amounts of liquid assets.

Such risks have always been handled through the provision of initial aid by central banks. From time to time solutions have been sought elsewhere, in deposit insurance, in the capital ratios fixed by the Basle agreements, in the degree of liquidity of assets, in the low risk of investment and in the careful use of "derived" products in relation to exchange and interest rates.

The same logic prevailed in the insurance sector, although here, the authorities were less worried about system risk, the degree of riskiness having always been kept under control by the monitoring authorities and by insurance companies themselves. Unlike bankers, insurers are risk-takers, selectors by vocation, who live off risks and risky consequences. Cautious by nature and timorous by profession, they have always drawn up theoretic formulae of reference and devised operative methods to limit the negative effect of events, whereby they have ensured that their assets and those of their colleagues are covered by various forms of reinsurance and co-insurance. Of late, however, regulations regarding caution in risk assumption have been introduced, including solvency margins, sector insurance, indicators of quality and quality ratings for operators.

For some time now a slow but subtle process whereby the products of the insurance service have been transformed into "goods" has been taking place. This transformation has been brought about by various developments:

- product simplification: one policy, one risk;

- reduction of the after-sales service: simple and quasi automatic procedures for the liquidation and payment of claims;

- less specialisation with sales channels;

- a coded system of categories linking sales channels with the various degrees of product complexity in insurance.

It goes without saying that the forces behind the transformation of products into goods are the same as those which brought about the process of deregulation, making for greater productivity and a reduction in unit profit per type of product. 
According to a study carried out by the McKinley firm, given increased deregulation, operative margins in the insurance sector as a percentage of premiums fell during the $80 \mathrm{~s}$ and $90 \mathrm{~s}$ : by $9.0 \%$ in Germany, $6.3 \%$ in Switzerland, $4.1 \%$ in France, $2.5 \%$ in the UK and by $2.6 \%$ in the USA.

It is also clear that the narrower the operative margins become the greater the risk of insolvency for banks and insurance companies. More attention should be given by the supervisory authorities to the figures from recent years in both sectors. These figures show that it is inadvisable to underestimate the potential risk of emerging situations.

Some progress has been made with quality control but much still remains to be done since high risks are still affecting the insurance and banking sector.

What, then, can be done?

It is totally unthinkable that we should return to the protected-sector methods that prevailed prior to deregulation. Monitoring and surveillance authorities will tend increasingly to curb rather than prevent, to indicate rather than order, to operate, that is, through "moral persuasion" as opposed to imposition and requisition.

If, however, "moral persuasion" proves ineffective, the only solution will be to attempt to influence the economic pre-conditions of operativity, in other words, to apply pressure in the seven areas listed earlier, after suitable updating and, where necessary, reorganisation. In any case it is highly desirable that bureaucratic trappings and useless cost controls be avoided. It would, for example, be unthinkable that we should:

- minimise opportunities rather than risks;

- destroy "diversity" in our attempts to reward managerial caution;

- nurture the tentacles of bureaucracy rather than reward efficient management.

But whatever we do, the overall effect of such procedures must be to foster and reward a sense of responsibility in banks and insurance companies.

\section{The minimum capital required for the incorporation of banks and insurance companies}

Given increased competition, decreasing operative margins, shrinking operative areas and increased company size, new enterprises must be asked to provide a minimum entry capital appropriate to the business programme they intend to develop and to the coverage they plan to provide as well as, it goes without saying, representative of the high profesional and moral standing of the promoters of such new enterprises.

\section{Reinforcement of the MSM}

In the insurance sector, the studies which have led to the formation of the minimum solvency margin (MSM) now date back 30 years. It was roughly established that, given a 5\% likelihood of insolvency for a life insurance company, the MSM should be set at around 4\% of the actuarial reserve and the Damages line at $16-18 \%$ of the premiums paid, irrespective, that is, of risk-type analysis, of the type of reinsurance available, or of the criteria for the calculation of the RM, RS and premium reserves.

If we pursue this rough method of calculation, it soon becomes clear that an insolvency threshold of $5 \%$ is unsustainable given the present structure and characteristics of the insurance market: with the advent of the service economy we have seen with the majority of 
insurance holders an increase in demand for insurance services; much attention has been given to the quality of before- and after-sales assistance; the introduction of unregulated fees has whetted competition and cut the technical and financial margins of insurer and banker; the increase in the number og distribution channels has had the effect of containing not only costs but, most of all, surcharges; through freedom of establishment and service, the European formation of a single market for insurance and capital has meant an increase in the variety of banking and insurance services on offer and a widening of the range of costs and marketing policies available; increased volatility of yields on the capital for increased diversification and incompatibility between markets has made forecast and operative balance-sheets.

To conclude, given the radical change in the operative environment, the threshold of the insolvency risk of Life-insurance and Damages companies and banks should be lowered; in the case of life insurance, the risk could be lowered from $5 \%$ to $1 \%$, raising the MSM from $4 \%$ to $10 \%$ of the RM; for the Damages sector, the MSM could be raised from $16-18 \%$ of the premiums to $50 \%$; and as far as banks are concerned, the suggestions of the EC could be combined with those of the Bank for Settlements in Basle.

While agreement in principle on these objectives is easy to reach, it is not quite so easy to answer the following question: Who is to bear the cost of such an operation? Should it be the capitalist partner of the bank and insurance company or the clientele of insurance holders who agree to pay a "security surcharge" to guarantee that the institutions "hold firm"? According to actuarial science, in a fair game situation in the long term, the bank is bound to go bankrupt. To avoid this risk, the State promulgates public regulations whereby the inequity of the game can be accepted and regulated and the advantage of the inequity turned over to the bank in order to obviate or minimise the risk of insolvency.

According to this scientific approach, the bank and the insurance company should be authorised by the supervisory authorities to "load" the cost of their services with a security surcharge in order to avoid an insolvency which would seriously prejudice the interests of bank customer and insurance holder alike. To conclude, it is argued that such is the priority attached by both customer and insurance holder to the avoidance of insolvency that both will agree to the relative cost increase involved. The deregulation of the $80 \mathrm{~s}$ and $90 \mathrm{~s}$ has cast doubt on the validity of this approach, and it is now apparent that the "security" of both bank and insurance company must be covered by the capital on which the managerial and entrepreneurial responsibility of the firms depends.

It goes without saying that, for banks and insurance companies, the weight of this responsibility will be counterbalanced by the economic advantage of successful performance.

\section{The low risk structure of assets}

From the USA comes the suggestion that the structure of investments of insurance companies be settled outside any legislative framework, the use of low risk lines of investment, such as government securities, municipal bonds, bonded securities and monetary instruments being favoured. In banks, the criteria for granting loans to clients have become stricter. The recent exercise of making loans more secure has made it necessary to obtain a rating in advance on the holder of the loan, before concession and definition of all the other clauses of the loan can be made. 
This attempt to move back towards the illiberal policies of state control of the past should be totally rejected. Indeed, this aspect of the riskiness of the insurance and banking business should on the contrary be considered within a wider framework, making it legitimate to form the actuarial and financial reserves of equilibrium, already in operation in some EC markets.

\section{Criteria for asset and liability evaluation}

It is obvious that this quantitative approach will fail to reflect reality unless it is linked to considerations of quality. There is no sense in reinforcing the minimum solvency margin and creating reserves of technical and financial equilibrium without strict criteria for the evaluation of the assets and liabilities of banks and insurance companies. Evaluation criteria must therefore be given due attention.

The high volatility of the cost of money as seen day after day on the capital markets creates great variation in the value of assets, whether they be real estate, farms, mortgage loans, shares or bonds.

However debatable, market prices still represent a fixed reference point with respect to historical values, cost values or values formed in other ways. Whenever we move away from market prices we risk introducing elements of uncertainty into the formation of the balancesheet.

The choice of the criteria for the evaluation of liabilities, such as mathematical reserves, claims reserves and premium reserves, is certainly more complex.

The trade has, however, gradually selected a series of evaluation criteria which the sector should refer to and respect permanently.

Indeed, changes should be excluded on principle and, where exceptionally they are made, they should be fully justified and highlighted in the balance report.

\section{The formation of reserves of financial equilibrium (RFE)}

The recent erratic nature of the financial markets calls for the formation of reserves of financial equilibrium (RFE), in addition, that is, to actuarial reserves of equilibrium (linked to variations in the claims to premiums ratio) and to exchange reserves of equilibrium (linked to fluctuations in the exchange ratios), in order to achieve a truer representation of the banking and insurance balances and a stabilisation of the balance outcome in the long term.

This means, at the end of the financial year, placing in a reserve all increases and decreases in value, whether realised or not, that result from share and bond portfolios, after fixing a maximum limit of variations for the shares and bonds: for example $5 \%$ for bonds, $20-30 \%$ for shares. It goes without saying that any overshoot of these maximum limits should affect the profit and loss account of the bank or insurance company.

\section{The formation of actuarial reserves of equilibrium}

The technicians of the banks and insurance companies draw up theoretical and operational formulae; their voices are heard at conferences and round tables, but never seem to reach the ears of the legislator, whose job it is to determine the overall thrust of legislation. 
Banks and insurance companies are bodies which tend towards the maximisation of profits within a framework of accepted riskiness which should never - under any circumstances - place the survival of the firm in jeopardy. The pursuit of profit without a safety net or its abandon out of excess prudence and adversity to risk are the two extremes of entrepreneurial choice: failure follows excessive or nil adversity to risk, success lies in the soundness of one's risk-selection policy.

The aim of the reserve of equilibrium is to minimise the likelihood of insolvency for a bank or insurance company following an excessive number of outstanding payments or damage claims. These reserves operate roughly by forming a reserve in banks over years with low outstanding payments and in insurance companies over years marked by low damage ratios. Drawdowns on such reserves can thus be made in negative years.

\section{Processing and promoting the ratings}

The banking and insurance sectors are no longer protected sectors. Indeed they are becoming increasingly similar to the other sectors which are subject to market laws, competition and insolvency. However it must be said that neither the public authorities nor public opinion are willing to accept the consequences of this competitive situation. Their reticence and refusal are manifest principally in two ways: everywhere the authorities are pushing for the creation of sectoral rescue organisms in case of crisis and everywhere also they are obstructing the untrammelled operation of the law of the market - either legally or through administrative process.

It is well known that sectoral guarantee funds have been formed everywhere in the banking sector and the same trend is taking place in insurance especially in life insurance. It goes without saying that it is possible to achieve such second level guarantee provided guarantees at the primary level - company security provision - have been adequately reinforced.

As regards the law of the market and competition, it is of fundamental importance that the authorities work toward the formation and promotion of quality ratings so that the customer is able to assess and judge for himself. Only where this situation obtains can the customer be persuaded to participate in the negative consequences of insolvency and the market to bear responsibility for the excesses of competition that are intrinsic to its very operation. 